\title{
Impact of Epidural Analgesia in Labour on Neonatal and Maternal Outcomes
}

\author{
Nora Tawhid Söderholm1, Sahruh Turkmen1,2* \\ ${ }^{1}$ Department of Obstetrics and Gynecology, Örnsköldsvik Hospital, Örnsköldsvik, Sweden \\ ${ }^{2}$ Department of Clinical Sciences, Obstetrics and Gynecology, Umeå University, Umeå, Sweden \\ Email: *sahruh.turkmen@umu.se
}

How to cite this paper: Söderholm, N.T. and Turkmen, S. (2018) Impact of Epidural Analgesia in Labour on Neonatal and Maternal Outcomes. Open Journal of Obstetrics and Gynecology, 8, 767-779. https://doi.org/10.4236/ojog.2018.89080

Received: June 1, 2018

Accepted: July 29, 2018

Published: August 1, 2018

Copyright (c) 2018 by authors and Scientific Research Publishing Inc. This work is licensed under the Creative Commons Attribution International License (CC BY 4.0).

http://creativecommons.org/licenses/by/4.0/

(c) (i) Open Access

\begin{abstract}
Aim: To evaluate the effect of epidural analgesia during labour on neonatal-maternal outcomes. Methods: A retrospective cohort study of nulliparous parturients who gave birth in Västernorrland County, Sweden, over a 2-year period between 2015 and 2016. Neonatal outcomes (Apgar score at $5 \mathrm{~min}$ and umbilical cord arterial blood gases), maternal outcomes (perineal injury, total bleeding volume and maternal satisfaction with birth) and labour parameters (mode of delivery and the durations of labour and postpartum hospital stay) were evaluated. Results: The study cohort consisted of 1449 women with singleton pregnancies. Patients were divided into two groups according to whether during labour they were administered epidural analgesia using bupivacaine and sufentanil (EDA group, $\mathrm{n}=615$ ) or not (non-EDA group, $\mathrm{n}=$ 834). The rate of assisted vaginal delivery was significantly higher in the EDA group than in the non-EDA group $(15.6 \%$ and $11.3 \%$, respectively, $\mathrm{p}<0.05)$, whereas the rates of caesarean section were similar. The duration of the active phase of labour was significantly longer in the EDA group than in the non-EDA group (489 $\pm 217 \mathrm{~min}$ versus $371 \pm 210 \mathrm{~min}$, respectively, $\mathrm{p}<$ 0.001). The Apgar score at $5 \mathrm{~min}$ and umbilical cord blood $\mathrm{pH}$ were lower and the base deficit greater in the EDA group ( $<0.001, \mathrm{p}<0.001$ and $\mathrm{p}<$ 0.01 , respectively). Bleeding volume was similar between the groups after adjusting for gestational age. Women in the EDA group were more satisfied with their labour experience, as measured by the visual analogue scale $(\mathrm{p}<$ 0.05). Conclusion: The results of this study suggest that EDA affects delivery and neonatal-maternal outcomes negatively, but increases the mother's satisfaction with labour.
\end{abstract}

\section{Keywords}

Obstetric, Visual Analogue Scale, Maternal Satisfaction, Apgar Score, Perineal Injury, Mode of Delivery, Foetal Blood Gases 


\section{Introduction}

Labour may be the most painful experience many women ever encounter [1]. The experience is unique for each woman and is influenced by emotions, motivation, cognitive ability, and social and cultural circumstances. The mother's physiological response to the pain affects maternal and foetal well-being as well as the delivery process [2]. The pain itself is not life-threatening for healthy parturients, but it can lead to neuropsychological consequences such as postnatal depression [3] and post-traumatic stress disorder [4].

Good pain relief is one of the most important factors related to patient satisfaction [5] [6]. Epidural analgesia is the most popular method of pain relief and considered the gold standard for pain relief during labour [5] [7]. In Sweden, more than half of the primiparous women who gave birth at hospitals in 2015 were given epidural anaesthesia; however, this rate varies among counties (37\% $66 \%)$ [8]. Its advantages include no effect on consciousness and reduced levels of stress hormones in the blood; it also acts to lower blood pressure in cases of preeclampsia or hypertension [9] [10] [11]. Although epidural analgesia is considered safe for both the parturient and baby, some transient side effects have been reported (mainly in the mother), including itching, shaking, nausea, insufficient pain relief, urinary retardation, muscle weakness, elevated temperature, headache, local pain at the site of injection and hypotension [7] [11] [12] [13] [14]. Epidural analgesia can also be used for delivery by caesarean section [15].

Several studies have shown that epidural analgesia can affect labour and neonatal-maternal outcomes negatively in terms of increases in labour duration, rate of instrumental deliveries [10] [13], oxytocin use, temperature [12] [13] and risk of foetal malrotation [12] [16]. However, many other studies have shown no effect of epidural analgesia on the mode of delivery or on neonatal outcomes [14]. The controversial results of such studies raise women's concerns regarding the side effects and safety of epidural analgesia, thus leading to a hesitation to use epidural analgesia [17].

The aim of this study is to evaluate the effects of epidural analgesia (EDA) using bupivacaine and sufentanil on labour and neonatal-maternal outcomes among nulliparous women.

\section{Methods}

We conducted a retrospective cohort study of all nulliparous parturients who used epidural analgesia and gave birth in Västernorrland County, Sweden over a 2-year period between 2015 and 2016. The study was approved by the Regional Ethical Review Board of Umeå, Sweden.

The study group consisted of nulliparous women who received epidural analgesia of bupivacaine and sufentanil during the active phase of labour. Matched women who did not receive epidural analgesia during the same period were recruited as the control group. The inclusion criteria were primiparity, age 18 - 40 years, gestational age between $\geq 37+0$ and $42+0$ weeks, active phase of labour 
with cervical dilation $\geq 4 \mathrm{~cm}$, singleton pregnancy, spontaneous initiation of labour and cephalic presentation. The exclusion criteria were multiple pregnancy, gestational age of $<37+0$ or $\geq 42+0$ weeks, cephalopelvic disproportion, foetal malpresentation, cervical dilation $<4 \mathrm{~cm}$, medical complications (e.g. preeclampsia, hypertension, diabetes), neurological disease and an allergy to anaesthesia. In this study, we included only women who were in the active phase of labour. The active phase of labour was defined as the presence of at least two of the following three criteria: regular painful contractions (every $3-5 \mathrm{~min}$ for more than 1 hour), membrane rupture and cervical dilation $>3 \mathrm{~cm}$.

The method of analgesia: In the epidural group, a 17-gauge epidural catheter (SIMS Portex LTD, Hythe, UK) was inserted under aseptic precautions in the lateral position at L3 - L4 with the loss of resistance to saline technique. The epidural catheter was then secured and the parturient placed in the supine position with left uterine displacement with the head of the bed elevated 20 - 30 degrees. For pain relief, a ready to use solution of bupivacaine $0.6 \mathrm{mg} / \mathrm{l}$ and sufentanil $0.5 \mu \mathrm{g} / \mathrm{ml}$ in $100 \mathrm{ml}$ bag. $10 \mathrm{ml}$ of mixture is given as a test dose and therapeutic dose. After five minutes, continuous infusion of $5-10 \mathrm{~mL} / \mathrm{h}$ of the analgesic solution was started to maintain labour analgesia.

The women who met the above criteria were identified by searching their medical records using Obstetrix (Siemens Corporation, Upplands Väsby, Sweden), a Swedish electronic medical record system designed specifically for prenatal care and childbirth. In Obstetrix, pregnancies are followed in a logical and structured manner, from enrolment in the prenatal health care centre, to arrival at the maternity unit, to time of delivery.

Maternal and neonatal parameters were recorded. The maternal parameters were as follows: duration of the active phase of labour (cervical dilation $\geq 4 \mathrm{~cm}$ until delivery), duration of postpartum hospital stay (from delivery until discharge), mode of delivery, perineal tearing (anal sphincter damage), overall satisfaction with their childbirth experience (measured by the visual analogue scale [VAS]) and total intrapartum bleeding volume. The VAS is a simple method with good validity and reliability that is often used in patient satisfaction surveys [18]. Here, it was used to assess the mother's overall satisfaction with the birth at the time of her discharge from the hospital. The VAS comprised a straight horizontal line of fixed length $(100 \mathrm{~mm})$, each end representing either the worst imaginable (score of 1 ) or best possible (score of 10) birth experience. Perineal tears and injuries were classified into four grades according to the depth of injury and degree of anal sphincter involvement [19]. Grade 3 injuries involve the anal sphincter muscles, whereas grade 4 injuries additionally involve the intestinal mucosa (anal mucosa).

The neonatal outcomes were the Apgar score at $5 \mathrm{~min}$ and umbilical cord arterial blood gases ( $\mathrm{pH}$ and base excess [BE]). The demographic characteristics of the mother (age and body mass index [BMI]) were also analysed.

Statistical analysis: The statistical analyses were performed using the IBM 
SPSS 23 Statistical Program (IBM Corp., Armonk, NY, USA). The distribution of the continuous data was not tested for normality, but the sample size was judged to be large enough to use parametric testing [20]. The Chi-square test was used for categorical data. Student's t-test was used to assess differences in the continuous variables between the EDA and non-EDA groups. Pearson's correlation analysis was used to evaluate correlations. Analysis of covariance was used to determine the differences in continuous variables between the EDA and non-EDA groups after adjusting for gestational age. Logistic regression analysis with adjustment for confounders was used to identify the risk factors for perineal injury. The results of the logistic regression analyses are presented as the odds ratio (OR) and 95\% confidence interval. Categorical variables are expressed as proportions and numbers and continuous variables as means \pm standard deviation. In all tests, the level of significance was set at $\mathrm{p}<0.05$.

Power Analysis: Earlier study showed that epidural anaesthesia may cause a delay during the second phase of labour [21]. In order to detect a delay of 15 min, $\alpha=0.05$ and $\beta=0.80$, the size of study population will be 70 test subjects per group.

\section{Results}

A total of 1529 women met the selection criteria, and after applying the exclusion criteria, 1449 nulliparous women were enrolled in the study. The subjects were divided into two groups according to whether they had been given EDA (EDA group, $\mathrm{n}=615$ ) or not (non-EDA control group, $\mathrm{n}=834$ ) during labour. Some women had incomplete data, which is why the group sizes vary among the different parameters.

The baseline characteristics of both groups are shown in Table 1. Although all women in both groups had full-term pregnancies, gestational age was higher in the EDA group than in the non-EDA group $(\mathrm{p}<0.001)$. There was a significant difference in the delivery method between the groups, in that the rate of assisted vaginal delivery was significantly higher in the EPA group than in the non-EDA group $(15.6 \%$ and $11.3 \%$, respectively, $\mathrm{p}<0.05)$; however, the rate of caesarean section delivery was similar. The duration of the active phase was 118 min longer in the EDA group than in the non-EDA group $(\mathrm{p}<0.001)$. There was no significant difference in the length of postpartum hospital stay between the groups. Total bleeding volume was higher in the EDA group compared with the

Table 1. Demographics of the parturients enrolled in the study.

\begin{tabular}{cccc}
\hline & EDA (n) & Non-EDA (n) & p-value \\
\hline Age (years) & $26.8 \pm 4.4(615)$ & $26.9 \pm 4.4(834)$ & NS \\
BMI (m/ $\left./ \mathrm{kg}^{2}\right)$ & $24.4 \pm 4.3(588)$ & $24.3 \pm 4.6(791)$ & NS \\
Gestational age (weeks) & $40.08 \pm 1.2(615)$ & $39.86 \pm 1.2(834)$ & $<0.001$ \\
\hline
\end{tabular}

NS: non-significant; EDA: epidural analgesia using bupivacaine and sufentanil; BMI: body mass index; n: number of patients. 
non-EDA group, but the difference was not significant after adjusting for gestational age (Table 2).

The Chi-square test showed no difference between the two groups in terms of grade 3 or 4 perineal tears. EDA increased the risk of instrumental delivery (Table 2), which in turn increased the risk of anal sphincter injury. Logistic regression analysis revealed that EDA was not a significant risk factor for perineal injury (OR 1.56, 95\% CI $(0.95,2.56), \mathrm{p}>0.05)$. After adjusting for gestational age and mode of delivery, the OR remained non-significant (OR 1.47, 95\% CI $(0.90,2.42), \mathrm{p}>0.05$ and OR $1.47,95 \%$ CI $(0.89,2.43), \mathrm{p}>0.05$, respectively).

EDA showed no effect on the rate of caesarean sections (Table 2).

All of the women evaluated their childbirth experience using the VAS scale. Compared with the non-EDA-group, the VAS score was significantly higher in the EDA group, indicating a higher level of satisfaction in these women $(\mathrm{p}<$ 0.05, Table 2).

In the EDA group, the Apgar score at $5 \mathrm{~min}$, umbilical cord arterial blood $\mathrm{pH}$ and negative $B E$ were significantly lower $(\mathrm{p}<0.001$ and $\mathrm{p}<0.001, \mathrm{p}<0.01$ respectively) compared with the non-EDA group (Table 3 ). In both groups, the difference in BE between the groups was reduced after adjusting for gestational age in an analysis of covariance, but the difference remained significant. No significant effect of gestational age was seen on any of the other neonatal variables.

Table 2. Maternal and delivery outcomes.

\begin{tabular}{cccccc}
\hline & EDA (n) & $\%$ & Non-EDA (n) & $\%$ & p-value \\
\hline Mode of delivery & & & & & \\
Normal & $480(615)$ & 78.1 & $684(834)$ & 82.0 & NS \\
Instrumental & $96(615)$ & 15.6 & $94(834)$ & 11.3 & $<0.05$ \\
Caesarean section & $39(615)$ & 6.3 & $56(834)$ & 6.7 & NS \\
Postpartum hospital stay length (h) & $40 \pm 30(615)$ & & $39 \pm 27(834)$ & NS \\
Total bleeding (ml) & $423 \pm 315(581)$ & & $389 \pm 281(803)$ & NS \\
Perineal tears (grade 3/4) & $35(576)$ & 6.1 & $31(778)$ & 4.0 & NS \\
Satisfaction with childbirth (VAS) & $6.2 \pm 3.5(611)$ & $5.8 \pm 4.0(822)$ & $<0.05$ \\
Duration of active phase (min) & $489 \pm 217(229)$ & $371 \pm 210(186)$ & $<0.001$ \\
\hline
\end{tabular}

NS: non-significant; EDA: epidural analgesia using bupivacaine and sufentanil; VAS: visual analogue scale score; n: number of patients.

Table 3. Neonatal outcomes.

\begin{tabular}{cccc}
\hline & EDA (n) & Non-EDA (n) & p-value \\
\hline Apgar score at 5 min & $9.68 \pm 0.8(615)$ & $9.81 \pm 0.6(833)$ & $<0.001$ \\
Umbilical cord arterial pH & $7.19 \pm 0.095(490)$ & $7.21 \pm 0.09(663)$ & $<0.001$ \\
Base excess (mmol/l) & $-6.93 \pm 3.7(486)$ & $-6.14 \pm 4.1(661)$ & $<0.01$ \\
Neonatal weight $(\mathrm{g})$ & $3507.4 \pm 445.9(612)$ & $3513.3 \pm 466.4(799)$ & NS \\
\hline
\end{tabular}

NS: non-significant; EDA: epidural analgesia using bupivacaine and sufentanil; n: number of patients. 
Correlation analysis revealed many associations between study parameters, but most were weak. In the EDA group, gestational age was negatively correlated with $\mathrm{BE}(\mathrm{r}=-0.112, \mathrm{p}<0.05$; versus non-EDA group: $\mathrm{r}=-0.074, \mathrm{p}=0.052)$ and length of postpartum hospital stay $(r=-0.109, \mathrm{p}<0.01)$ but positively correlated with duration of the active phase $(r=0.216, p<0.05$; versus non-EDA group: $r=$ $0.135, \mathrm{p}=0.058)$ and bleeding volume $(\mathrm{r}=0.093, \mathrm{p}<0.05)$; versus non-EDA group $(r=0.109, p>0.01)$. In the non-EDA group, gestational age was negatively correlated with umbilical cord arterial blood $\mathrm{pH}(\mathrm{r}=-0.121, \mathrm{p}<0.001$; versus EDA group: $r=-0.78, p=0.075)$ and length of postpartum hospital stay $(\mathrm{r}=-0.121, \mathrm{p}<0.001)$.

We performed correlation analyses to identify any parameters affecting the difference in VAS score of birth experience between the two groups. In the EDA group, the VAS score showed a positive correlation with the Apgar score at 5 $\min (r=0.083, p<0.05$; versus non-EDA group: $r=0.64, p=0.06)$ but negative correlations with the length of postpartum hospital stay $(r=-0.35, p<0.001)$ and bleeding volume $(\mathrm{r}=-0.096, \mathrm{p}<0.05)$. In the non-EDA group, the VAS score was negatively correlated with the length of postpartum hospital stay $(\mathrm{r}=$ $-0.295, \mathrm{p}<0.001)$ and bleeding volume $(\mathrm{r}=-0.140, \mathrm{p}<0.001)$.

In both groups, maternal BMI was positively correlated with neonatal weight (EDA group: $\mathrm{r}=0.189, \mathrm{p}<0.001$; non-EDA group: $\mathrm{r}=0.112, \mathrm{p}<0.001$ ). In the non-EDA group, there was a negative correlation between the Apgar score at 5 min and BMI $(r=-0.071, p<0.05$; versus EDA group $r=-0.004, p=0.9)$. In both groups, the Apgar score was positively correlated with BE (EDA group: $r=$ $0.236, \mathrm{p}<0.001$; non-EDA group: $\mathrm{r}=0.24, \mathrm{p}<0.001$ ) and umbilical cord arterial blood $\mathrm{pH}$ (EDA group: $\mathrm{r}=0.239, \mathrm{p}<0.001$; non-EDA group: $\mathrm{r}=0.263, \mathrm{p}<$ $0.001)$.

\section{Discussion}

The results of this study showed that EDA affected labour by increasing its duration and by increasing the likelihood of instrumental delivery, but had no effect on the caesarean section rate. Although the neonates in the EDA group had lower scores for well-being parameters compared with those in the non-EDA group, the values were within normal limits.

Our findings are in agreement with those of many earlier studies [13] [22] [23] [24] [25]; however, some other studies failed to find any association between EDA use and an increased rate of instrumental delivery [26] [27] [28] or caesarean section [13] [22] [26] [27] [28]. On the other hand, some observational studies have shown that the use of EDA during the earlier phases of labour can increase the rate of caesarean section delivery [29] [30], but this result was not confirmed in more recent randomised controlled studies [31] [32].

Cambic et al. reported an association between severe and early onset of labour pain and poorer obstetric outcomes and overall childbirth experience [31]. Lieberman et al. suggested that women who had EDA were slightly shorter, had a 
longer gestational period and delivered slightly heavier babies compared with those who did not have EDA, and that they had enrolled earlier in the labour process and had slower cervical dilation even before they received EDA [29]. We detected no differences in BMI or neonatal weight between the two groups, although gestational age was higher in the EDA group.

As well as a longer duration of the active phase of labour in the EDA group, there was also an association with higher gestational age, which could be the factor underlying the prolonged active phase of labour, and could perhaps explain why instrumental deliveries were more frequent in this group. However, the analysis of gestational age as a cause of this difference showed no effect of this parameter as a confounder. On the other hand, Thorp et al. showed a link between instrumental delivery and EDA use whether cervical dilation was rapid or slow [30]. Some studies investigated the duration of the first stage of labour in parturients administered EDA and found no effect of EDA on duration [13] [22]. In contrast, an earlier study showed that in nulliparous women, EDA increases the duration of the first stage of labour by approximately $30 \mathrm{~min}$ [23], and this finding has been supported by other studies [33] [34]. A meta-analysis suggested that EDA prolongs the first stage of labour by approximately $42 \mathrm{~min}$ [35]. However, other studies showed that EDA use during early-stage labour shortens the first stage of labour compared with opioid pain relief [32] or compared with EDA use later in labour [36].

As in our study, many other studies showed that EDA increases the risk of instrumental delivery [13] [23], which in turn can increase the risk of more serious perineal injuries [37]. An earlier study indicated that severe perineal injuries are not caused by EDA itself but rather by other factors [38]. In a large systematic review, however, an association was found between grade $3 / 4$ perineal tears and EDA [25]. Robinson et al. showed that EDA is strongly associated with grade 3/4 perineal tears, but after adjusting for other factors (e.g. neonatal weight, oxytocin use and rates of instrumental delivery and episiotomy, all of which were more frequent in the EDA group), these associations were no longer observed [39]. In our study, there was a small but non-significant difference between the groups, in that the EDA group had a higher rate of grade 3/4 perineal tears. We found a significantly higher bleeding volume at birth in the EDA group, and bleeding volume was positively correlated with perineal injury in both groups, but neither of the group's bleeding volume ranges exceeded the postpartum haemorrhage cut-off volume $(\geq 1000 \mathrm{ml})$. After adjusting for gestational age as a confounder, the difference in total bleeding volume between the groups was no longer significant.

A previous study revealed an association of EDA with an increased risk of induction of labour, episiotomy, instrumental delivery, prolonged second stage of labour and more severe maternal perineal injury, all of which increase the risk of postpartum bleeding [40].

In an Australian study, a relationship was observed between EDA and retained placenta, but not between EDA and postpartum bleeding; however, this 
result was questionable because the analyses were not adjusted for confounding factors [41]. In contrast, another study showed that the risk of postpartum haemorrhage doubled when EDA was used, and the risk remained even after correction for multiple maternal- and pregnancy-related factors [42]. Mangann et al. confirmed the association between EDA use and increased postpartum bleeding [43]. Earlier studies showed that EDA increases the rate of oxytocin use [12] [13], suggesting that uterine contractions are adversely affected by EDA, which in turn can contribute to greater bleeding, a prolonged active phase of labour and an increased rate of instrumental delivery. Although we found an increase in bleeding volume in the EDA group, the association detected between gestational age and bleeding may suggest gestational age to be the underlying cause of the difference in bleeding volume between the groups because of the older gestational age in the EDA group compared with the non-EDA group.

The present findings of lower values in the EDA group of Apgar score at 5 min, umbilical cord arterial blood $\mathrm{pH}$ and negative $\mathrm{BE}$ indicate that $\mathrm{EDA}$ use during labour has a negative impact on neonates. A Cochrane study showed that the incidence of foetal asphyxia (Apgar score at $5 \mathrm{~min}<7$ ) was not increased among women using EDA compared with those not using EDA [13]. In a systematic review, the authors found (in 33 of the 34 articles) no connection between EDA use and the Apgar score at $5 \mathrm{~min}$ [25], whereas another study suggested an association between EDA use and a low Apgar score at $5 \mathrm{~min}(<7)$ [42]. Leighton and Halpern, on the other hand, showed that EDA reduces the risk of a low Apgar score at $1 \mathrm{~min}(<7)$ (OR: 0.54), suggesting positive effects of EDA on placental circulation. They also showed that EDA did not affect neonatal oxygenation, umbilical cord arterial blood $\mathrm{pH}$ or the Apgar score at $5 \mathrm{~min}$ [14]. This can be explained by the finding that pain relief leads to reduced activation of the mother's sympathetic nervous system and may be beneficial to placental circulation, which improves the neonate's acid-base status [2]. Even during the course of a normal and uncomplicated delivery, the foetus undergoes a number of periods of reduced oxygen supply due to uterine contractions, which decreases the placental circulation. These short hypoxic episodes are usually well tolerated, as the foetus has several defence mechanisms to cope with impaired oxygenation [44]. Umbilical cord arterial blood $\mathrm{pH}$ is an important outcome parameter in obstetric research because a low $\mathrm{pH}$ is strongly correlated with neonatal mortality and morbidity [45]. Major abnormalities in blood $\mathrm{pH}$ are not considered compatible with survival, so it is extremely important that the body maintains a normal $\mathrm{pH}$ range; to achieve this, the body has several buffer systems that regulate changes in the hydrogen concentration [44]. Both $\mathrm{pH}$ and $\mathrm{BE}$ are useful measurements to assess the rate of foetal metabolic acidosis that may occur during labour. However, $\mathrm{pH}$, which is used most frequently, is not the best parameter for estimating the cumulative exposure to perinatal hypoxia because its logarithmic scale does not provide a linear measurement of acid accumulation. Both respiratory and metabolic changes affect $\mathrm{pH}$. BE, however, changes linearly with the level of me- 
tabolic acid accumulation and is also adapted for variations in the partial pressure of carbon dioxide [44] [46]. Lieberman et al. suggested that a lower umbilical cord blood $\mathrm{pH}$ can predict a poor neonatal outcome (low Apgar score) better than can a lower BE. They evaluated the effect of EDA on umbilical cord blood gases after adjusting for neonatal outcomes, and concluded that EDA use is not associated with umbilical cord arterial blood $\mathrm{pH}$ [25]. A meta-analysis suggested that EDA has positive effects on the BE level in the umbilical cord artery [47]. In that same study, $\mathrm{BE}$ was more sensitive than $\mathrm{pH}$ as an indicator of neonatal acidosis because umbilical cord arterial blood $\mathrm{pH}$ can be increased by the mother's hyperventilation, which is commonly induced by pain. Thus, women with inadequate pain relief may have higher umbilical cord arterial blood $\mathrm{pH}$ than that of those with good pain relief, which may partly explain the higher $\mathrm{pH}$ in the non-EDA group in our study. In our study, the lower $\mathrm{pH}$ in the umbilical cord artery of neonates whose mothers used EDA is of no clinical significance, as both groups had an Apgar score at $5 \mathrm{~min}>7$, which is correlated with good long-term outcomes [48]; however, new-borns in the EDA group potentially experienced greater stress and consumed more reserves (lower $\mathrm{BE}$ ) to compensate for the poor conditions (low $\mathrm{pH}$ ). In a healthy foetus with normal reserves, a decrease in $\mathrm{pH}$ (Table 3) has no clinical significance, but for a vulnerable foetus, even a slight decrease in $\mathrm{pH}$ may be important, because the rate of unfavourable neurological outcomes increases when the $\mathrm{pH}$ decreases below 7.1 [49].

Maternal satisfaction at birth is becoming increasingly important in our modern healthcare system; however, its assessment is difficult because it is a multifactorial subject for which no gold standard exists. One potential method of measuring satisfaction is the well-known VAS. In this study, the women in the EDA group had a higher VAS score for overall childbirth experience, suggesting that they were more satisfied with their experience than women who did not use EDA. This finding has been supported by other studies, suggesting that EDA is the gold standard resulting in adequate pain relief and increased patient satisfaction [24] [31] [33]. Effective pain management correlates strongly and positively with increased patient satisfaction [50] [51] [52]. As expected, in our study, the VAS score was negatively associated with the length of postpartum hospital stay, total bleeding volume and mode of delivery in both groups and with perineal injury in the non-EDA group. This suggests that women with a less complicated delivery are more satisfied with their childbirth experience. The childbirth experience is important for a woman, and a negative experience can affect the mother and her family relationships adversely in the long run [53]. However, in contrast to our results, a Cochrane study suggested that parturients who used EDA were no more satisfied with their childbirth experience than those who did not use EDA [13]. Although the childbirth experience and woman's satisfaction are multidimensional and difficult to evaluate using a scale, the VAS is still an important and helpful instrument for healthcare professionals to improve maternal care and allocate resources more efficiently. 


\section{Conclusion}

In conclusion, our study suggests that EDA adversely affects the mode of delivery and neonatal-maternal parameters, but that women who use EDA are more satisfied with their overall childbirth experience. EDA has become a popular method for reducing pain during labour. The impacts of epidural use are not limited to the mother and can extend to the neonate at birth. It is important for healthcare staff to provide information on this topic to all pregnant women. The limitations of this study are those characteristics of retrospective design that probably impacted or influenced the interpretation of the findings; therefore, more and better designed randomised prospective studies addressing the efficacy and safety of EDA are needed.

\section{Acknowledgements}

We are particularly grateful to Ulla Thelin, a research midwife; and to Erling Englund for his help with the data analysis. This work was supported by a grant from Sveriges Kommuner och Landsting (SKL-medel).

\section{Disclosure}

The authors have no conflicts of interest to declare in connection with this article.

\section{References}

[1] Melzack, R. (1984) The Myth of Painless Childbirth (the John J. Bonica Lecture). Pain, 19, 321-337. https://doi.org/10.1016/0304-3959(84)90079-4

[2] Cunningham, F.G. (2014) Williams Obstetrics. McGraw-Hill Medical, New York.

[3] Hiltunen, P., Raudaskoski, T., Ebeling, H. and Moilanen, I. (2004) Does Pain Relief during Delivery Decrease the Risk of Postnatal Depression? Acta Obstetricia et Gynecologica Scandinavica, 83, 257-261. https://doi.org/10.1111/j.0001-6349.2004.0302.x

[4] Soet, J.E., Brack, G.A. and DiIorio, C. (2003) Prevalence and Predictors of Women's Experience of Psychological Trauma during Childbirth. Birth, 30, 36-46. https://doi.org/10.1046/j.1523-536X.2003.00215.x

[5] Volmanen, P., Sarvela, J., Akural, E.I., Raudaskoski, T., Korttila, K. and Alahuhta, S. (2008) Intravenous Remifentanil vs. Epidural Levobupivacaine with Fentanyl for Pain Relief in Early Labour: A Randomised, Controlled, Double-Blinded Study. Acta Anaesthesiologica Scandinavica, 52, 249-255. https://doi.org/10.1111/j.1399-6576.2007.01509.x

[6] Madden, K., Middleton, P., Cyna, A.M., Matthewson, M. and Jones, L. (2016) Hypnosis for Pain Management during Labour and Childbirth. The Cochrane Database of Systematic Reviews, Cd009356. https://doi.org/10.1002/14651858.CD009356.pub3

[7] Gizzo, S., Noventa, M., Fagherazzi, S., Lamparelli, L., Ancona, E., Di Gangi, S., et al. (2014) Update on Best Available Options in Obstetrics Anaesthesia: Perinatal Outcomes, Side Effects and Maternal Satisfaction. Fifteen Years Systematic Literature Review. Archives of Gynecology and Obstetrics, 290, 21-34. 
https://doi.org/10.1007/s00404-014-3212-x

[8] The National Board of Health and Welfare - Socialstyrelsen (2015) Statistik om graviditeter, förlossningar och nyfödda barn.

http://www.socialstyrelsen.se/publikationer2017/2017-3-3/2017

[9] Gizzo, S., Di Gangi, S., Saccardi, C., Patrelli, T.S., Paccagnella, G., Sansone, L., et al. (2012) Epidural Analgesia during Labor: Impact on Delivery Outcome, Neonatal Well-Being, and Early Breastfeeding. Breastfeeding Medicine, 7, 262-268.

https://doi.org/10.1089/bfm.2011.0099

[10] Hasegawa, J., Farina, A., Turchi, G., Hasegawa, Y., Zanello, M. and Baroncini, S. (2013) Effects of Epidural Analgesia on Labor Length, Instrumental Delivery, and Neonatal Short-Term Outcome. Journal of Anesthesia, 27, 43-47. https://doi.org/10.1007/s00540-012-1480-9

[11] Gomar, C. and Fernandez, C. (2000) Epidural Analgesia-Anaesthesia in Obstetrics. European Journal of Anaesthesiology, 17, 542-558. https://doi.org/10.1097/00003643-200009000-00003

[12] Dickersin, K. (1989) Effective Care in Pregnancy and Childbirth. Oxford University Press, Oxford.

[13] Anim-Somuah, M., Smyth, R.M. and Jones, L. (2011) Epidural versus Non-Epidural or No Analgesia in Labour. The Cochrane Database of Systematic Reviews, Cd000331. https://doi.org/10.1002/14651858.CD000331.pub3

[14] Leighton, B.L. and Halpern, S.H. (2002) The Effects of Epidural Analgesia on Labor, Maternal, and Neonatal Outcomes: A Systematic Review. American Journal of $O b-$ stetrics \& Gynecology, 186, S69-S77.

[15] Hagberg, H., Maršál, K. and Westgren, M. (2014) Obstetrik. Studentlitteratur, Lund.

[16] Cheng, Y.W., Shaffer, B.L. and Caughey, A.B. (2006) Associated Factors and Outcomes of Persistent Occiput Posterior Position: A Retrospective Cohort Study from 1976 to 2001. The Journal of Maternal-Fetal \& Neonatal Medicine, 19, 563-568. https://doi.org/10.1080/14767050600682487

[17] Sng, B.L., Leong, W.L., Zeng, Y., Siddiqui, F.J., Assam, P.N., Lim, Y., et al. (2014) Early versus Late Initiation of Epidural Analgesia for Labour. The Cochrane Database of Systematic Reviews, Cd007238. https://doi.org/10.1002/14651858.CD007238.pub2

[18] Brokelman, R.B., Haverkamp, D., van Loon, C., Hol, A., van Kampen, A. and Veth, R. (2012) The Validation of the Visual Analogue Scale for Patient Satisfaction after Total Hip Arthroplasty. European Orthopaedics and Traumatology, 3, 101-105. https://doi.org/10.1007/s12570-012-0100-3

[19] Bulchandani, S., Watts, E., Sucharitha, A., Yates, D. and Ismail, K.M. (2015) Manual Perineal Support at the Time of Childbirth: A Systematic Review and Meta-Analysis. BJOG, 122, 1157-1165. https://doi.org/10.1111/1471-0528.13431

[20] Ejlertsson, G. (2003) Statistik för hälsovetenskaperna. Studentlitteratur, Lund.

[21] (2001) Handläggning av Normal Förlossning-State of the Art. The National Board of Health and Welfare-Socialstyrelsen, Stockholm.

[22] Leighton, B.L. and Halpern, S.H. (2005) Epidural Analgesia and the Progress of Labor. In: Halpern, S.H. and Douglas, M.J., Eds., Evidence-Based Obstetric Anesthesia, Blackwell Publishing Ltd., Oxford, 10-22. https://doi.org/10.1002/9780470988343

[23] Sharma, S.K., McIntire, D.D., Wiley, J. and Leveno, K.J. (2004) Labor Analgesia and Cesarean Delivery: An Individual Patient Meta-Analysis of Nulliparous Women. Anesthesiology, 100, 142-148. 
[24] Liu, E.H.C. and Sia, A.T.H. (2004) Rates of Caesarean Section and Instrumental Vaginal Delivery in Nulliparous Women after Low Concentration Epidural Infusions or Opioid Analgesia: Systematic Review. BMJ, 328, 1410. https://doi.org/10.1136/bmj.38097.590810.7C

[25] Lieberman, E. and O’Donoghue, C. (2002) Unintended Effects of Epidural Analgesia during Labor: A Systematic Review. American Journal of Obstetrics \& Gynecology, 186, S31-S68. https://doi.org/10.1016/S0002-9378(02)70181-6

[26] Segal, S., Su, M. and Gilbert, P. (2000) The Effect of a Rapid Change in Availability of Epidural Analgesia on the Cesarean Delivery Rate: A Meta-Analysis. American Journal of Obstetrics and Gynecology, 183, 974-978. https://doi.org/10.1067/mob.2000.106677

[27] Impey, L., MacQuillan, K. and Robson, M. (2000) Epidural Analgesia Need Not Increase Operative Delivery Rates. American Journal of Obstetrics and Gynecology, 182, 358-363. https://doi.org/10.1016/S0002-9378(00)70224-9

[28] Yancey, M.K., Pierce, B., Schweitzer, D. and Daniels, D. (1999) Observations on Labor Epidural Analgesia and Operative Delivery Rates. American Journal of $O b$ stetrics and Gynecology, 180, 353-359. https://doi.org/10.1016/S0002-9378(99)70213-9

[29] Lieberman, E., Lang, J.M., Cohen, A., D’Agostino, R., Datta, S. and Frigoletto, F.D. (1996) Association of Epidural Analgesia with Cesarean Delivery in Nulliparas. $O b$ stetrics \& Gynecology, 88, 993-1000. https://doi.org/10.1016/S0029-7844(96)00359-6

[30] Thorp, J.A., Eckert, L.O., Ang, M.S., Johnston, D.A., Peaceman, A.M. and Parisi, V.M. (1991) Epidural Analgesia and Cesarean Section for Dystocia: Risk Factors in Nulliparas. American Journal of Perinatology, 8, 402-410. https://doi.org/10.1055/s-2007-999426

[31] Cambic, C.R. and Wong, C.A. (2010) Labour Analgesia and Obstetric Outcomes. British Journal of Anaesthesia, 105, i50-i60. https://doi.org/10.1093/bja/aeq311

[32] Wong, C.A., Scavone, B.M., Peaceman, A.M., McCarthy, R.J., Sullivan, J.T., Diaz, N.T., et al. (2005) The Risk of Cesarean Delivery with Neuraxial Analgesia Given Early versus Late in Labor. The New England Journal of Medicine, 352, 655-665. https://doi.org/10.1056/NEJMoa042573

[33] Jain, S., Arya, V.K., Gopalan, S. and Jain, V. (2003) Analgesic Efficacy of Intramuscular Opioids versus Epidural Analgesia in Labor. International Journal of Gynecology \& Obstetrics, 83, 19-27. https://doi.org/10.1016/S0020-7292(03)00201-7

[34] Alexander, J.M., Sharma, S.K., McIntire, D.D. and Leveno, K.J. (2002) Epidural Analgesia Lengthens the Friedman Active Phase of Labor. Obstetrics \& Gynecology, $100,46-50$.

[35] Halpern, S.H., Leighton, B.L., Ohlsson, A., Barrett, J.F. and Rice, A. (1998) Effect of Epidural vs. Parenteral Opioid Analgesia on the Progress of Labor: A Meta-Analysis. JAMA, 280, 2105-2110. https://doi.org/10.1001/jama.280.24.2105

[36] Ohel, G., Gonen, R., Vaida, S., Barak, S. and Gaitini, L. (2006) Early versus Late Initiation of Epidural Analgesia in Labor: Does It Increase the Risk of Cesarean Section? A Randomized Trial. American Journal of Obstetrics \& Gynecology, 194, 600-605. https://doi.org/10.1016/j.ajog.2005.10.821

[37] Robinson, J.N., Norwitz, E.R., Cohen, A.P., McElrath, T.F. and Lieberman, E.S. (1999) Episiotomy, Operative Vaginal Delivery, and Significant Perinatal Trauma in Nulliparous Women. American Journal of Obstetrics \& Gynecology, 181, 1180-1184. https://doi.org/10.1016/S0002-9378(99)70104-3 
[38] Albers, L.L., Migliaccio, L., Bedrick, E.J., Teaf, D. and Peralta, P. (2007) Does Epidural Analgesia Affect the Rate of Spontaneous Obstetric Lacerations in Normal Births? Journal of Midwifery \& Women's Health, 52, 31-36.

https://doi.org/10.1016/j.jmwh.2006.08.016

[39] Robinson, J.N., Norwitz, E.R., Cohen, A.P., McElrath, T.F. and Lieberman, E.S. (1999) Epidural Analgesia and Third- or Fourth-Degree Lacerations in Nulliparas. Obstetrics \& Gynecology, 94, 259-262.

[40] Oyelese, Y. and Ananth, C.V. (2010) Postpartum Hemorrhage: Epidemiology, Risk Factors, and Causes. Clinical Obstetrics and Gynecology, 53, 147-156. https://doi.org/10.1097/GRF.0b013e3181cc406d

[41] St George, L. and Crandon, A.J. (1990) Immediate Postpartum Complications. Australian and New Zealand Journal of Obstetrics and Gynaecology, 30, 52-56. https://doi.org/10.1111/j.1479-828X.1990.tb03196.x

[42] Saunders, N.S., Paterson, C.M. and Wadsworth, J. (1992) Neonatal and Maternal Morbidity in Relation to the Length of the Second Stage of Labour. British Journal of Obstetrics and Gynaecology, 99, 381-385. https://doi.org/10.1111/j.1471-0528.1992.tb13753.x

[43] Magann, E.F., Evans, S., Hutchinson, M., Collins, R., Howard, B.C. and Morrison, J.C. (2005) Postpartum Hemorrhage after Vaginal Birth: An Analysis of Risk Factors. The Southern Medical Journal, 98, 419-422. https://doi.org/10.1097/01.SMJ.0000152760.34443.86

[44] Armstrong, L. and Stenson, B.J. (2007) Use of Umbilical Cord Blood Gas Analysis in the Assessment of the Newborn. Archives of Disease in Childhood. Fetal and Neonatal Edition, 92, F430-F434. https://doi.org/10.1136/adc.2006.099846

[45] Malin, G.L., Morris, R.K. and Khan, K.S. (2010) Strength of Association between Umbilical Cord $\mathrm{pH}$ and Perinatal and Long Term Outcomes: Systematic Review and Meta-Analysis. BMJ, 340, c1471. https://doi.org/10.1136/bmj.c1471

[46] Ross, M.G. (2011) Labor and Fetal Heart Rate Decelerations: Relation to Fetal Metabolic Acidosis. Clinical Obstetrics and Gynecology, 54, 74-82. https://doi.org/10.1097/GRF.0b013e31820a106d

[47] Reynolds, F., Sharma, S.K. and Seed, P.T. (2002) Analgesia in Labour and Fetal Acid-Base Balance: A Meta-Analysis Comparing Epidural with Systemic Opioid Analgesia. BJOG, 109, 1344-1353.

[48] Ehrenstein, V. (2009) Association of Apgar Scores with Death and Neurologic Disability. Clinical Epidemiology, 1, 45-53. https://doi.org/10.2147/CLEP.S4782

[49] Yeh, P., Emary, K. and Impey, L. (2012) The Relationship between Umbilical Cord Arterial pH and Serious Adverse Neonatal Outcome: Analysis of 51,519 Consecutive Validated Samples. BJOG, 119, 824-831. https://doi.org/10.1111/j.1471-0528.2012.03335.x

[50] Goodman, P., Mackey, M.C. and Tavakoli, A.S. (2004) Factors Related to Childbirth Satisfaction. Journal of Advanced Nursing, 46, 212-219. https://doi.org/10.1111/j.1365-2648.2003.02981.x

[51] Brown, S. and Lumley, J. (1994) Satisfaction with Care in Labor and Birth: A Survey of 790 Australian Women. Birth, 21, 4-13. https://doi.org/10.1111/j.1523-536X.1994.tb00909.x

[52] Brander, D. and Beinder, E. (2007) The Impact of Epidural Analgesia on Birth Experience. Zeitschrift für Geburtshilfe und Neonatologie, 211, 76-81. https://doi.org/10.1055/s-2007-960629

[53] Reynolds, J.L. (1997) Post-Traumatic Stress Disorder after Childbirth: The Phenomenon of Traumatic Birth. Canadian Medical Association Journal, 156, 831-835. 